\title{
Welcome from the National Archaeological Museum
}

\section{Alexandra Christopoulou}

National Archaeological Museum

Athens, Greece

Welcome from the National Archaeological Museum, in the original Greek, followed by an English translation.

From Antikythera to the Square Kilometre Array: Lessons from the Ancients, Kerastari, Greece

12-15 June 2012 


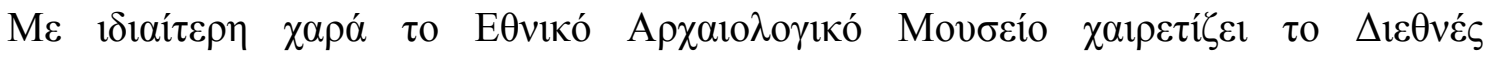

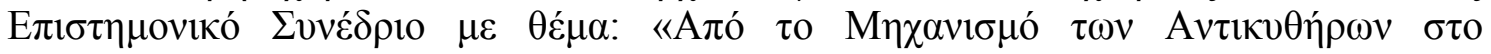

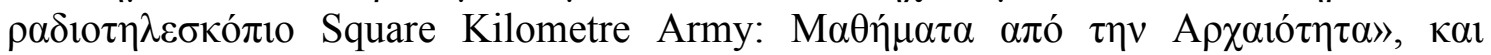

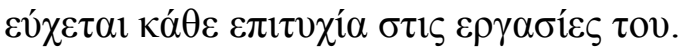

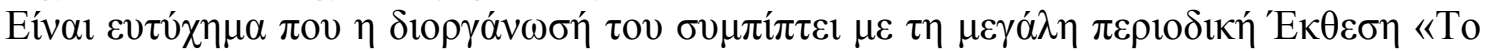

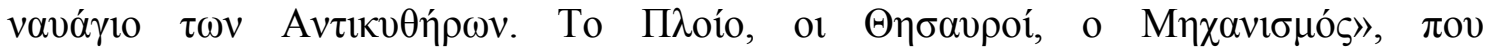

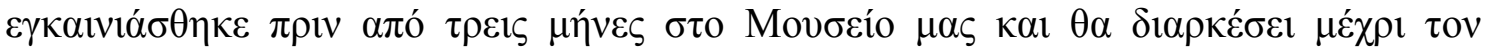

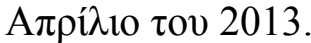

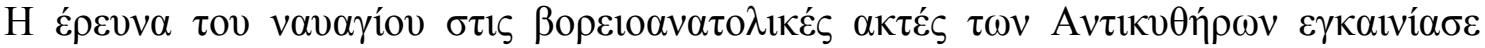

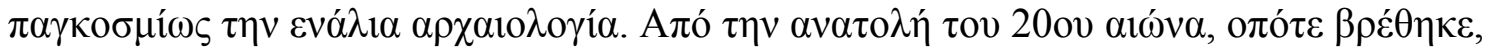

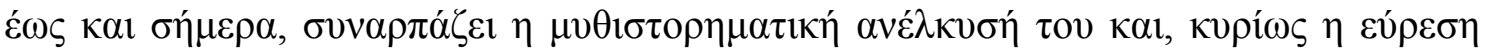

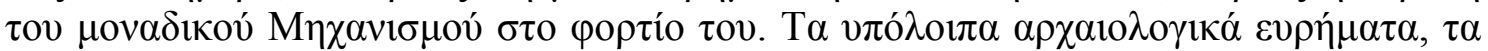

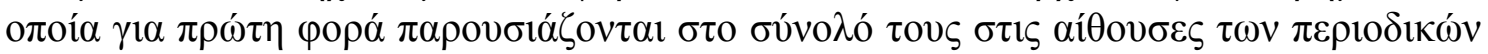

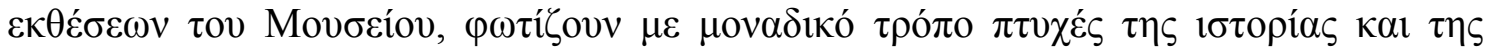

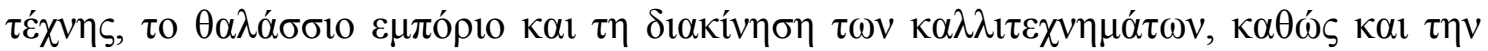

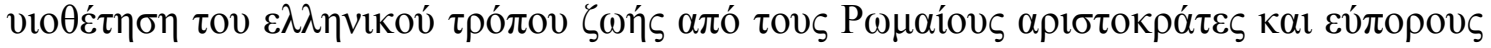

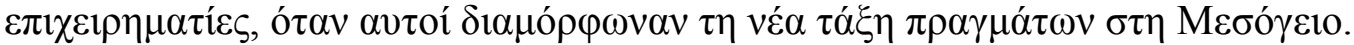

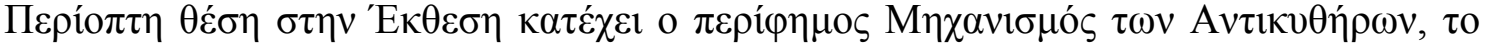

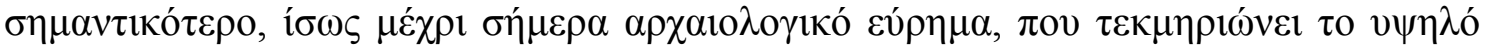

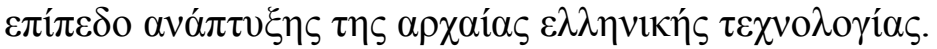

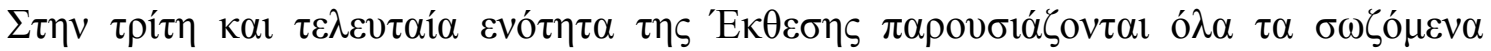

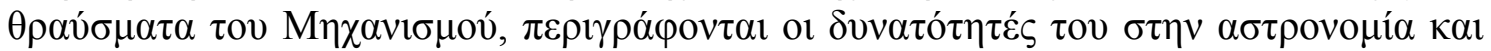

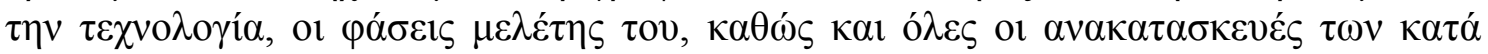

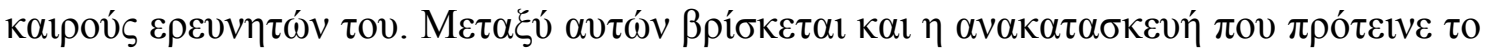
A

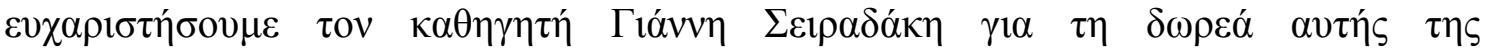

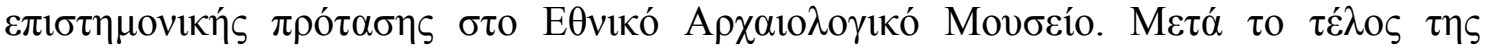

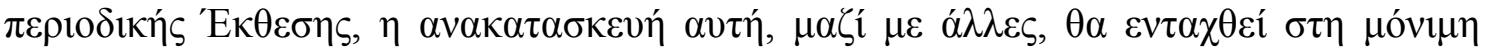

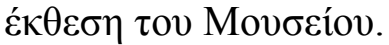

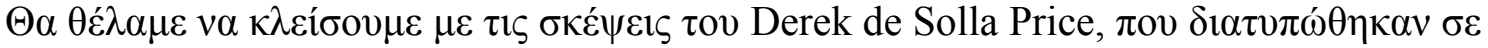

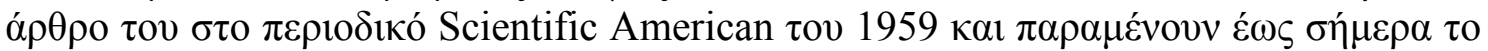

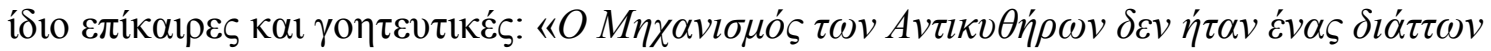

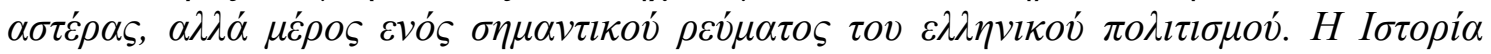

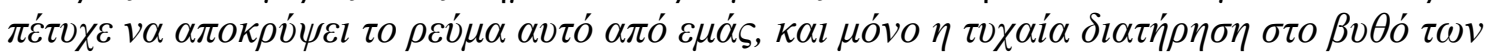

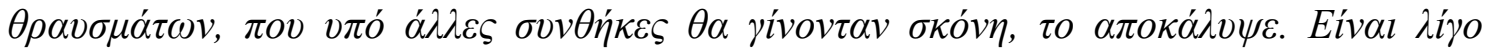

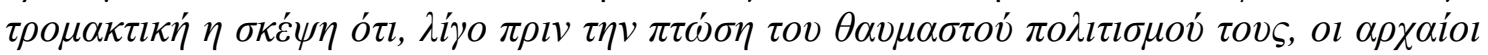

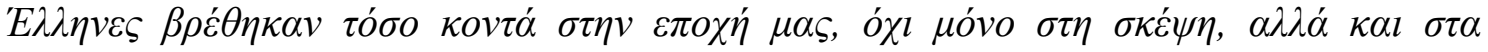

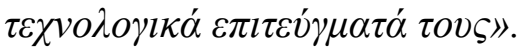

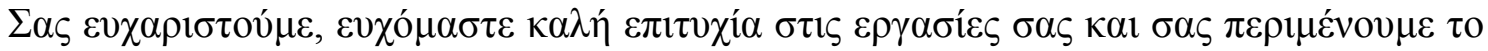

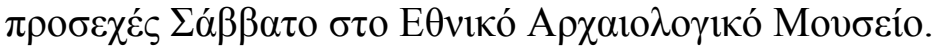

A $\theta$ ńva, Ioúvios 2012 


\section{English translation:}

With great joy the National Archaeological Museum welcomes the International Workshop "From Antikythera to the Square Kilometre Army: Lessons from the Ancients," and wishes you every success in your work.

It is fortunate that the organization of the workshop coincides with the major periodical Exhibition "The Antikythera Shipwreck. The Ship, the Treasures, the Mechanism", which was launched three months ago in our Museum and will run until April 2013. The exploration of the wreck on the northeastern coast of Antikythera initiated underwater archeology worldwide. From the dawn of the 20th century, when the wreck was found, to this day, popular imagination has been fascinated by its legendary marine excavation and, most importantly, by the unique Mechanism found in its load. The other archaeological finds, which are presented for the first time in their entirety in the halls of the Museum's temporary exhibitions, illuminate in a unique way aspects of history and art, maritime trade and exchange of artefacts, as well as the adoption of the Greek way of life by Roman aristocrats and wealthy businessmen, when they formed the new status in the Mediterranean.

Prominent position in the exhibition is held by the famous Antikythera Mechanism, perhaps the most important archaeological find to date, documenting the high level of ancient Greek technology.

The third and final section of the Exhibition presents all the surviving fragments of the Mechanism, describes the issues related to astronomy and technology, and describes the basic stages of the study and all the reconstructions and interpretations by the various researchers. There is included the reconstruction proposed by the Aristotle University of Thessaloniki. Here once again we thank Prof. John. H.Seiradakis for the donation of this scientific reconstruction to the National Archaeological Museum. At the end of this temporary Exhibition, this reconstruction, along with others, will join the Museum's permanent exhibition.

We would like to close with the thoughts of Derek de Solla Price printed in an article in the Scientific American magazine in 1959 and which remain as valid and charming today: "The Antikythera mechanism was no flash in the pan but was a part of an important current in Hellenistic civilization. History has contrived to keep that current dark to us, and only the accidental underwater preservation of fragments that would otherwise have crumbled to dust has now brought it to light. It is a bit frightening to know that just before the fall of their great civilization the ancient Greeks had come so close to our age, not only in their thought, but also in their scientific technology. "

With our thanks and best wishes for success in your work, we are looking foreward to welcoming you next Saturday at the National Archaeological Museum.

Athens, July 2012

Alexandra Christopoulou, $\mathrm{PhD}$

Deputy Director 